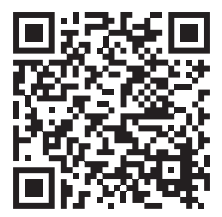

\title{
Enfermedad de Kawasaki y SARS-CoV-2, reporte de un caso
}

\author{
Adoniram Carrasco Castillo, ${ }^{*}$ Adán Cuatecontzi Romero, ${ }^{\ddagger}$ César Augusto Zárate Morales, ${ }^{\S}$ \\ Azucena del Carmen Grajales Morales," Luis Román Ramírez Palacios"
}

\section{RESUMEN}

La enfermedad de Kawasaki (EK) es una vasculitis de los vasos de pequeño y mediano calibre. Recientemente en la pandemia por el coronavirus tipo 2 del síndrome respiratorio agudo grave (SARS-CoV-2) han sido reportados brotes de casos con EK y otros cuantos con síndrome inflamatorio multisistémico en niños (MIS-C). Describimos el caso de un bebé de 10 meses de edad ingresado y diagnosticado con la EK clásica, que también dio positivo a infección por SARS-CoV-2 y que tuvo buena respuesta al tratamiento con inmunoglobulina endovenosa y dosis altas de ácido acetilsalicílico. El caso se justifica por la presentación clínica de COVID-19 pediátrico y la posible asociación con la EK.

Palabras clave: Enfermedad de Kawasaki, SARS-CoV-2, COVID-19.

\section{ABSTRACT}

Kawasaki disease $(K D)$ is a vasculitis of the small and medium caliber vessels. Outbreaks of cases with KD and a few others with multisystemic inflammatory syndrome in children (MIS-C) have recently been reported in the pandemic for the severe acute respiratory syndrome coronavirus type 2 (SARSCoV-2). We describe the case of a 10-month-old baby admitted and diagnosed with classical KD, who also tested positive for SARS-CoV-2 infection and had a good response to treatment with intravenous immunoglobulin and high doses of acetylsalicylic acid. The case is justified by the clinical presentation of pediatric COVID-19 and the possible association with KD.

Keywords: Kawasaki disease, SARS-CoV-2, COVID-19.

\section{INTRODUCCIÓN}

La enfermedad infecciosa conocida como COVID-19 (el nuevo nombre se toma de las palabras "corona», «virus» y disease, mientras que 19 representa el año en que surgió), es causada por el nuevo virus SARSCoV-2. Tanto el virus como la enfermedad eran desconocidos antes de que se presentará el brote epidémico en la provincia de Hubei, Wuhan, China en diciembre de 2019. El primer caso en México se confirmó el 28 de febrero del $2020^{1,2}$ y la Organización Mundial de la Salud (OMS) declaró la enfermedad como pandemia el 11 de marzo del 2020. ${ }^{3}$ En México, el 16 de marzo de 2020 la Secretaría de Salud implementó como medida preventiva la Jornada Nacional de Sana Distancia, aceptada en el vocabulario como cuarentena poblacional. ${ }^{4}$

\footnotetext{
* Servicio de Neumología y Endoscopia Pediátrica. Hospital de la Niñez Oaxaqueña. Oaxaca, México.

₹ Servicio de Reumatología Pediátrica. Hospital de la Niñez Oaxaqueña. Oaxaca, México.

§ Servicio de Cardiología Pediátrica. Hospital de la Niñez Oaxaqueña. Oaxaca, México.

" Servicio de Pediatría. Hospital de la Niñez Oaxaqueña. Oaxaca, México.

『 Jefe del Laboratorio de Virología y Biología Molecular. Laboratorio Estatal de Salud Pública de Oaxaca.
} 
En China, el 2.1\% de los casos reportados pertenecían a pacientes menores de 19 años y de estos casos, sólo el $0.2 \%$ evolucionó a enfermedad severa o fatal. ${ }^{5}$ En México, al 29 de abril del 2020, se reportaron 389 casos confirmados en menores de 20 años, que representan el $2.2 \%$ del total de casos, estando el mayor porcentaje (42\%) en el rango de edad de 15 a 19 años, siendo más frecuente en varones. ${ }^{6}$

Si bien las manifestaciones clínicas más frecuentes son la fiebre y la tos, en una serie de 78 casos pediátricos de los Estados Unidos de Norte América, 68\% (53 casos) no presentaron fiebre. ${ }^{7}$ Otras manifestaciones clínicas reportadas son rinorrea, odinofagia, conjuntivitis, artralgias, mialgias, disnea, cefalea o irritabilidad, síntomas gastrointestinales tales como diarrea, vómito y dolor abdominal. ${ }^{8}$ Recientemente se han reportado manifestaciones cutáneas como signo clínico asociado a COVID-19. ${ }^{9}$

La enfermedad de Kawasaki (EK) es una vasculitis aguda de la infancia y la principal causa de enfermedad cardiaca adquirida en niños de países desarrollados, con un $50 \%$ de los casos ocurridos en menores de dos años y un $80 \%$ en menores de cinco años. ${ }^{10}$ La EK se caracteriza clínicamente por la presencia de fiebre, conjuntivitis no supurativa bilateral, eritema de labios y de la mucosa oral, edema en las extremidades, exantema y adenopatía cervical. El diagnóstico de EK "clásica» se considera en quienes presentan fiebre durante cinco días junto con al menos cuatro de cinco criterios clínicos en ausencia de un diagnóstico alternativo. La complicación cardiaca más importante es el desarrollo de lesiones coronarias, las cuales se presentan en 15 a $25 \%$ de

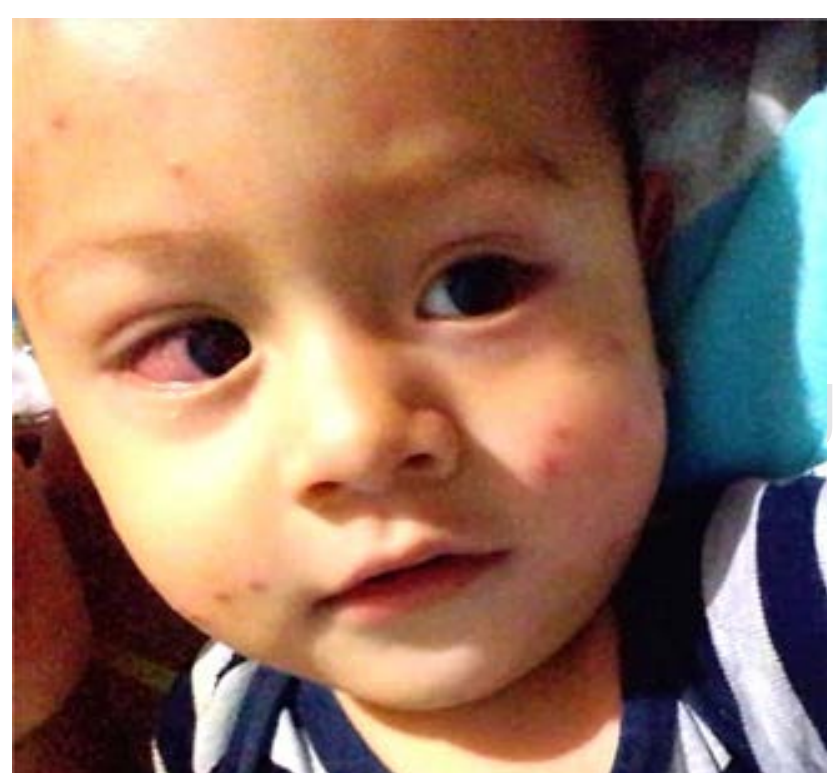

Figura 1: Hiperemia conjuntival unilateral no supurativa.

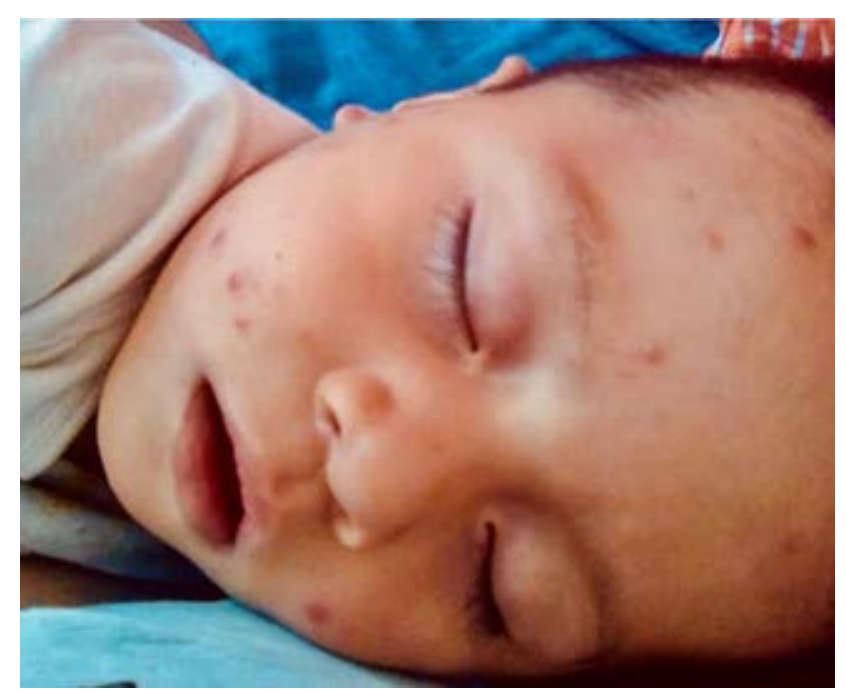

Figura 2: Hiperemia de labios, los cuales están fisurados.

los casos no tratados de la enfermedad. ${ }^{11,12}$ La etiología sigue siendo desconocida a pesar de varias décadas de investigación, postulándose un origen infeccioso. Recientemente en Nueva York se reportaron 15 niños hospitalizados con síntomas compatibles con un síndrome inflamatorio multisistémico que podría estar relacionado con COVID-19, los pacientes experimentaron fiebre persistente y características de la EK o características del síndrome de choque tóxico. ${ }^{13}$

Debido a que se trata de un nuevo padecimiento, la información relacionada con COVID-19 está sujeta a constante actualización a medida que avanzan los reportes de casos.

Los niños con EK, posiblemente relacionado con la infección por SARS-CoV-2, pueden tener algunas o todas las características de la EK. El caso que presentamos a continuación se trata de enfermedad de Kawasaki clásica asociada con infección por el SARS-CoV-2.

\section{CASO CLÍNICO}

Se trata de un masculino de 10 meses de edad. Producto de la segunda gesta, nació de término por vía vaginal y sin complicaciones. Alimentado con leche materna hasta los dos meses de edad. Carga genética para autoinmunidad por línea materna, ya que dos tías tienen artritis reumatoide. Acuden a urgencias por fiebre de 39 grados centígrados de cinco días de evolución. La fiebre se presentaba diario sin predominio de horario y no cedía con antipiréticos. Desde el primer día presentó exantema en el tronco. A los tres días se agrega hiperemia de labios y lengua, posterior edema de pies y al quinto día eritema con descamación de la piel en la zona genital. Niega la madre contacto con personas. 
Vol. 29, Núm. 2・ Mayo-Agosto 2020

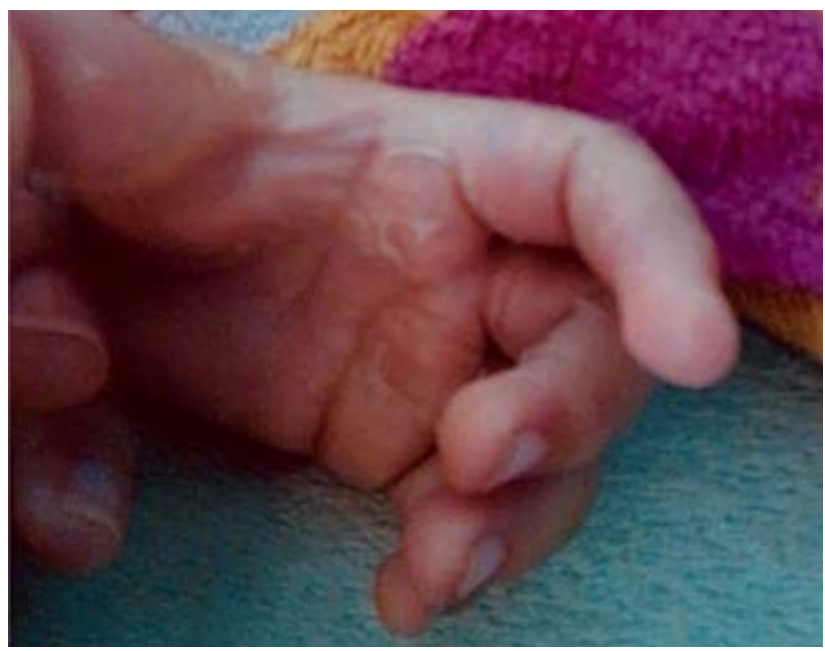

Figura 3: Edema y descamación «en guante» de manos.

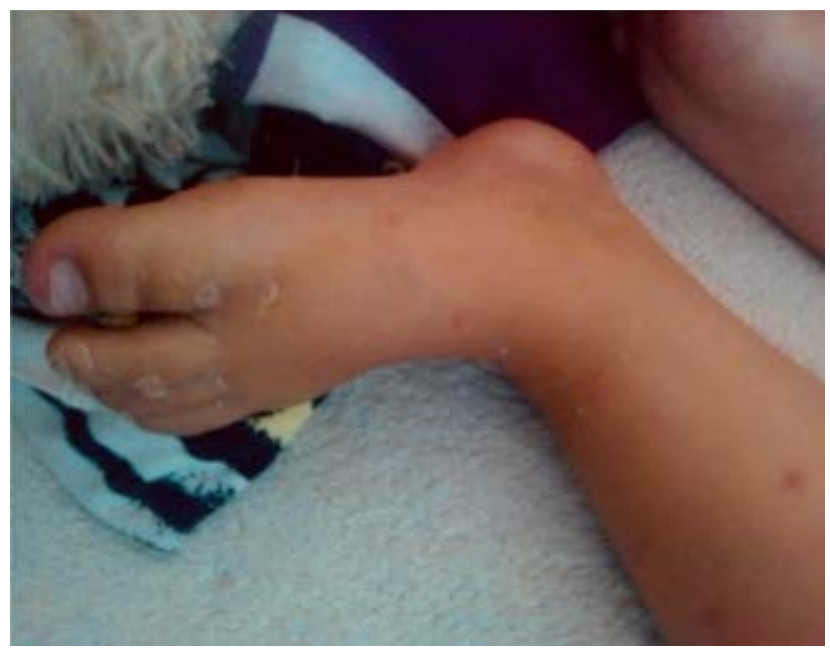

Figura 4: Edema de pies con descamación.

A la exploración física encontramos peso $9.9 \mathrm{~kg}$, taIla $77 \mathrm{~cm}$, FC 130/min, FR: $32 / \mathrm{min}$, temperatura: $38^{\circ} \mathrm{C}$. Lactante irritable, hiperemia conjuntival unilateral no supurativa (Figura 1), hiperemia de labios, los cuales están fisurados (Figura 2) y lengua muy enrojecida con leve hipertrofia de papilas gustativas. Adenopatías cervicales anteriores bilaterales menores de $1 \mathrm{~cm}$. Precordio rítmico, tórax con movimientos normales, auscultación de campos pulmonares normal, sin integrar algún síndrome pleuropulmonar. Abdomen globoso, sin datos patológicos. Eritema y edema en palmas, las cuales tienen una descamación característica en aspecto de «guante» (Figura 3) y edema en plantas con descamación fina (Figura 4). Descamación de los dedos (Figura 5). Dermatosis en la zona genital con eritema, escama y escoriaciones (Figura 6), además de eritema morbiliforme generalizado. Con lo anterior se integra enfermedad de Kawasaki y se hospitaliza.

Por reportes de síndrome hiperinflamatorio asociado con COVID-19, se toma muestra nasal y faríngea para realizar RT-PCR-SARS-CoV-2 la cual se reporta positiva (Figura 7).

Estudios sanguíneos de su ingreso: hemoglobina $10.9 \mathrm{~g} / \mathrm{dL}$, hematocrito $32.5 \%$, plaquetas $340,000 / \mu \mathrm{L}$, leucocitos $8,160 / \mu \mathrm{L}$, neutrófilos $57 \%$, linfocitos $28 \%$, monocitos $9 \%$, eosinófilos $6 \%$. Velocidad de sedimentación globular $40 \mathrm{~mm} / \mathrm{h}$. Grupo sanguíneo y $\mathrm{Rh}$ «O» positivo. Glucosa 84 mg/dL, gamma glutamil transferasa 132 U/L, proteína $\mathrm{C}$ reactiva $96 \mathrm{mg} / \mathrm{L}$.

Radiografía de tórax normal (Figura 8).

Estudios a las 48 horas: hemoglobina $11.5 \mathrm{~g} / \mathrm{dL}$, hematocrito $32.4 \%$, plaquetas $496,000 / \mu \mathrm{L}$, leucocitos $6,280 / \mu \mathrm{L}$. Neutrófilos $41 \%$ (con granulaciones cito tóxicas), linfocitos $40 \%$, monocitos $10 \%$, eosinófilos $8 \%$. Velocidad de sedimentación globular $35 \mathrm{~mm} / \mathrm{h}$. Gamma glutamil transferasa 98 U/L. Proteína C reactiva 12 mg/L.

Desde su llegada, se inicia manejo con inmunoglobulina humana intravenosa a dosis de $2 \mathrm{~g} / \mathrm{kg}$ y ácido acetil-

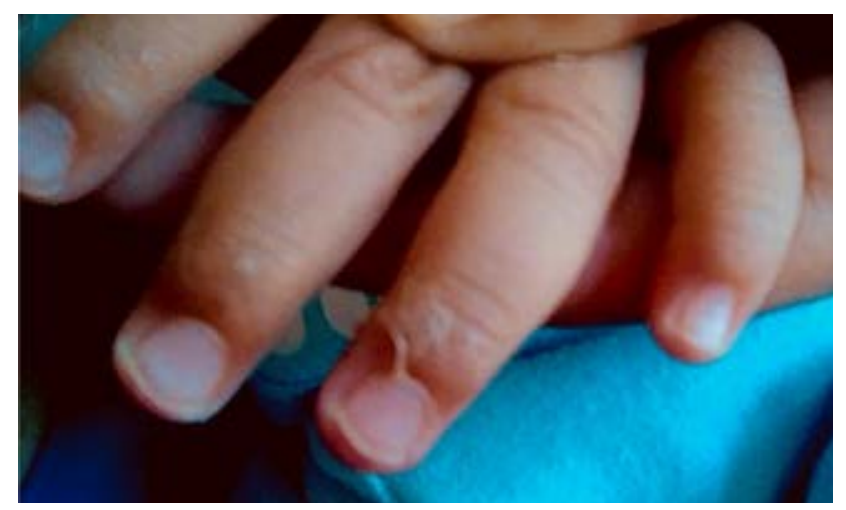

Figura 5: Descamación de los dedos.

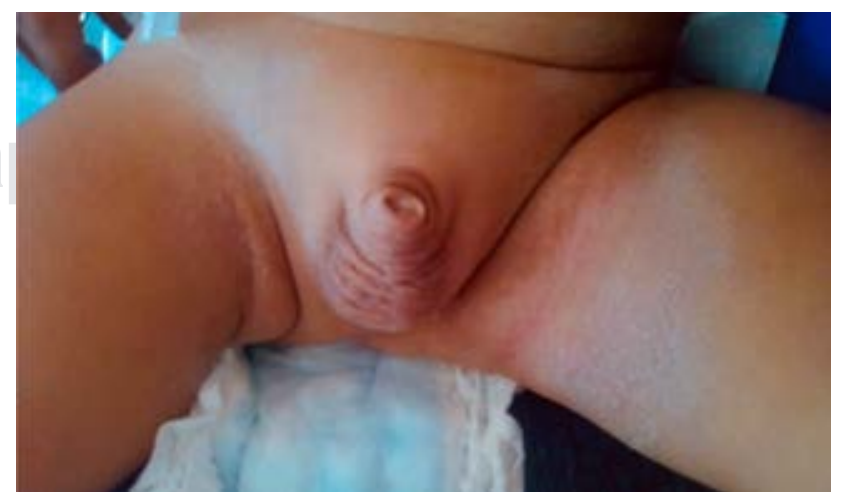

Figura 6: Dermatosis en la zona genital con eritema, escama y escoriaciones. 


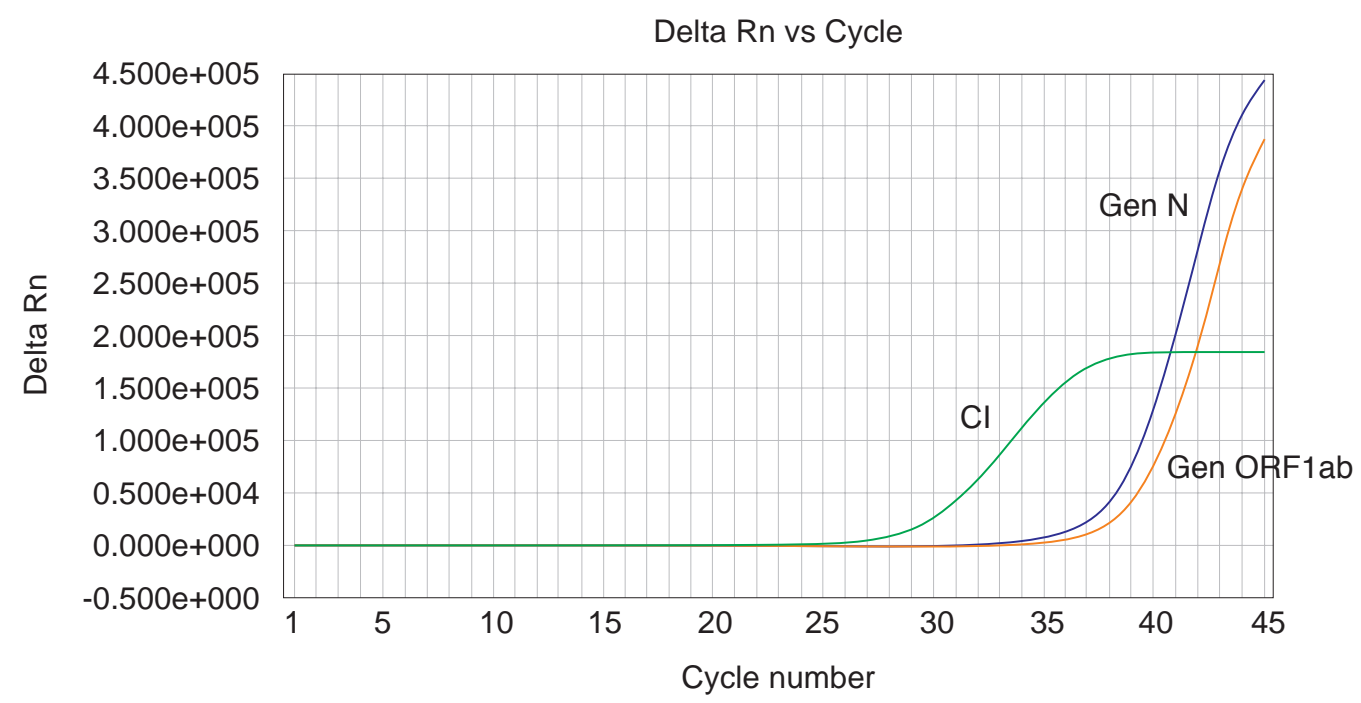

Selected Detector: All

Well(s): C5

Document: Plate1 09-05-20 (Standard Curve)

Figura 7: Biología molecular. Screening de genes SARS-CoV-2. Prueba positiva. EI RNA es extraído a partir de los especímenes respiratorios, posteriormente el DNA complementario es sintetizado en un solo paso y amplificado mediante PCR a tiempo real. La detección se lleva a cabo utilizando oligonucleótidos específicos y una sonda marcada con una molécula fluorescente y otra apantalladora (quencher) para detectar SARS-CoV-2. La detección se realiza a través de la retrotranscripción y posterior amplificación a tiempo real de la secuencia diana, produciéndose ambas reacciones en el mismo pocillo. Tras el aislamiento del RNA, se sintetiza el DNA complementario a la secuencia diana gracias a la retrotranscriptasa o transcriptasa inversa. Posteriormente, la identificación de SARS-CoV-2 se lleva a cabo mediante la reacción en cadena de la polimerasa utilizando oligonucleótidos específicos y una sonda marcada con fluorescencia que hibridan con una región diana conservada de los genes ORF1ab y $N$.

salicílico $100 \mathrm{mg} / \mathrm{kg} /$ día. La fiebre cedió al terminar la infusión de inmunoglobulina, la hiperemia de labios y boca disminuyeron considerablemente. El paciente egresó a las 72 horas sin complicaciones, con ácido acetilsalicílico a $5 \mathrm{mg} / \mathrm{kg} /$ día. En la revisión a las tres semanas sin evidencia de lesión coronaria por ecocardiograma (Figuras 9 y 10), con estudios de laboratorios: hemoglobina $10.5 \mathrm{~g} / \mathrm{dL}$, hematocrito $27.2 \%$, plaquetas $285000 / \mu \mathrm{L}$, leucocitos 7,210, linfocitos 38\%, neutrófilos 31\%, bandas $3 \%$, eosinófilos $21 \%$, monocitos $8 \%$, velocidad de sedimentación globular 32 , proteína $\mathrm{C}$ reactiva negativa, gamma glutamil transferasa $18 \mathrm{U} / \mathrm{L}$.

\section{DISCUSIÓN}

La enfermedad de Kawasaki es una vasculitis multisistémica que afecta arterias de pequeño y mediano calibre, aguda, autolimitada, de lactantes y preescolares, ${ }^{14}$ descrita por Tomisaku Kawasaki en $1967^{15}$ y considerada como la primera causa de enfermedad cardiaca adquirida en países desarrollados. Se caracteriza por fiebre, conjuntivitis bilateral no exudativa, eritema de los labios y de la mucosa oral, cambios en las extremidades como

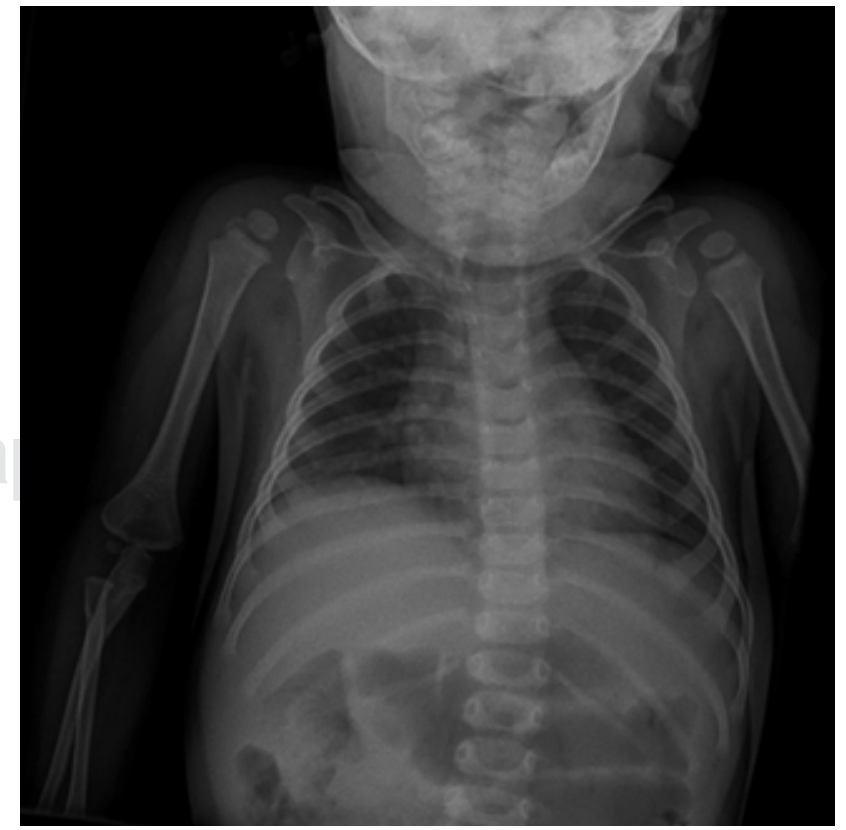

Figura 8: Radiografía de tórax AP normal. 
Vol. 29, Núm. 2 • Mayo-Agosto 2020

edema y descamación, presencia de exantema troncal polimorfo y linfadenopatía cervical. Si no se otorga un tratamiento apropiado, entre el 18 y $23 \%$ de los pacientes pueden desarrollar aneurismas cardiacos ${ }^{16}$ que, finalmente, pueden desencadenar muerte súbita, infarto agudo de miocardio o enfermedad cardiaca isquémica crónica. Aunque se considera de causa desconocida, se ha postulado que el causante es un agente infeccioso ubicuo que sólo produce enfermedad clínica manifiesta en personas genéticamente susceptibles. ${ }^{17}$

Son muchos los agentes etiológicos postulados como causa de la EK, tales como la toxina de Staphylococcus aureus, productora del síndrome del choque tóxico, Propionibacterium acnes, Streptococcus mitis, virus herpes tipo 6, virus de Epstein-Barr, Leptospira sp., Streptococcus $\alpha$ hemolítico, entre muchos otros, sin haberse podido comprobar inequívocamente la causalidad. ${ }^{18}$ Rowley y colaboradores, mediante un anticuerpo sintético, encontraron un antígeno presente en el epitelio respiratorio y en los macrófagos de niños con EK. Esto, aunado al hallazgo de células plasmáticas productoras de IgA en el tejido peribronquial, ${ }^{19,20}$ es altamente sugestivo de un agente infeccioso que ingresa a través del tracto respiratorio y es procesado por los macrófagos.

En el año 2005, Esper y su grupo publicaron un artículo ${ }^{21}$ en el cual detectaron, mediante técnicas moleculares (RT-PCR), la presencia de coronavirus humano New Haven (HCoV-NH) en las secreciones respiratorias de $72.7 \%$ (8/11) de los pacientes con EK, que eran positivos para dos tipos de genes de este coronavirus, en comparación con el 4.5\% (1/22) de los controles; por ello, en ese año propusieron a este virus como el agente etiológico de la enfermedad..$^{22}$ No obstante, en un estudio multicéntrico, ${ }^{23}$ adelantado en tres instituciones de atención pediátrica (dos en los Estados Unidos y una en Holanda), y después de analizar en cinco laboratorios 57 muestras de secreciones respiratorias provenientes de 48 niños con diagnóstico de enfermedad de Kawasaki, solamente se encontró positividad para el HCoV-NL63/ $\mathrm{NH}$ en $1(2 \%)$ de los 48 pacientes estudiados (basado en la técnica de RT-PCR). Esto sugiere que la infección respiratoria exclusivamente por este coronavirus no está asociada con la enfermedad de Kawasaki.

Según los datos disponibles hasta la fecha, los niños con COVID-19 tienen mejor pronóstico que los adultos, siendo pocos los casos graves reportados, y en casos leves se recuperan en 1-2 semanas después del inicio de la enfermedad. ${ }^{7}$ Muchos pueden cursar incluso asintomáticos. Sin embargo, en los últimos dos meses un pequeño grupo de pacientes ha desarrollado una respuesta inflamatoria sistémica significativa, requiriendo manejo en Unidad de Cuidados Intensivos y de otros especialistas pediatras. A este síndrome se le ha denominado síndrome inflamatorio multisistémico en niños (MIS-C). ${ }^{24}$ Los niños con este nuevo síndrome, posiblemente relacionado con COVID-19, pueden tener algunas o todas las características de la enfermedad de Kawasaki. Estos niños tienen fiebre persistente, inflamación y evidencia de disfunción de uno o varios órganos (choque, trastorno cardiaco, respiratorio, renal, gastrointestinal o neurológico) y pueden o no dar positivo a COVID-19..$^{25}$

Las presentaciones tipo Kawasaki se manejaron como enfermedad de Kawasaki según las indicaciones de la American Heart Association; en el presente caso
Figura 9:

$$
\begin{array}{r}
\text { A. Imagen ecocardiográfica } \\
\text { que muestra coronaria } \\
\text { derecha normal. B. Imagen } \\
\text { ecocardiográfica que muestra } \\
\text { coronaria izquierda normal. }
\end{array}
$$
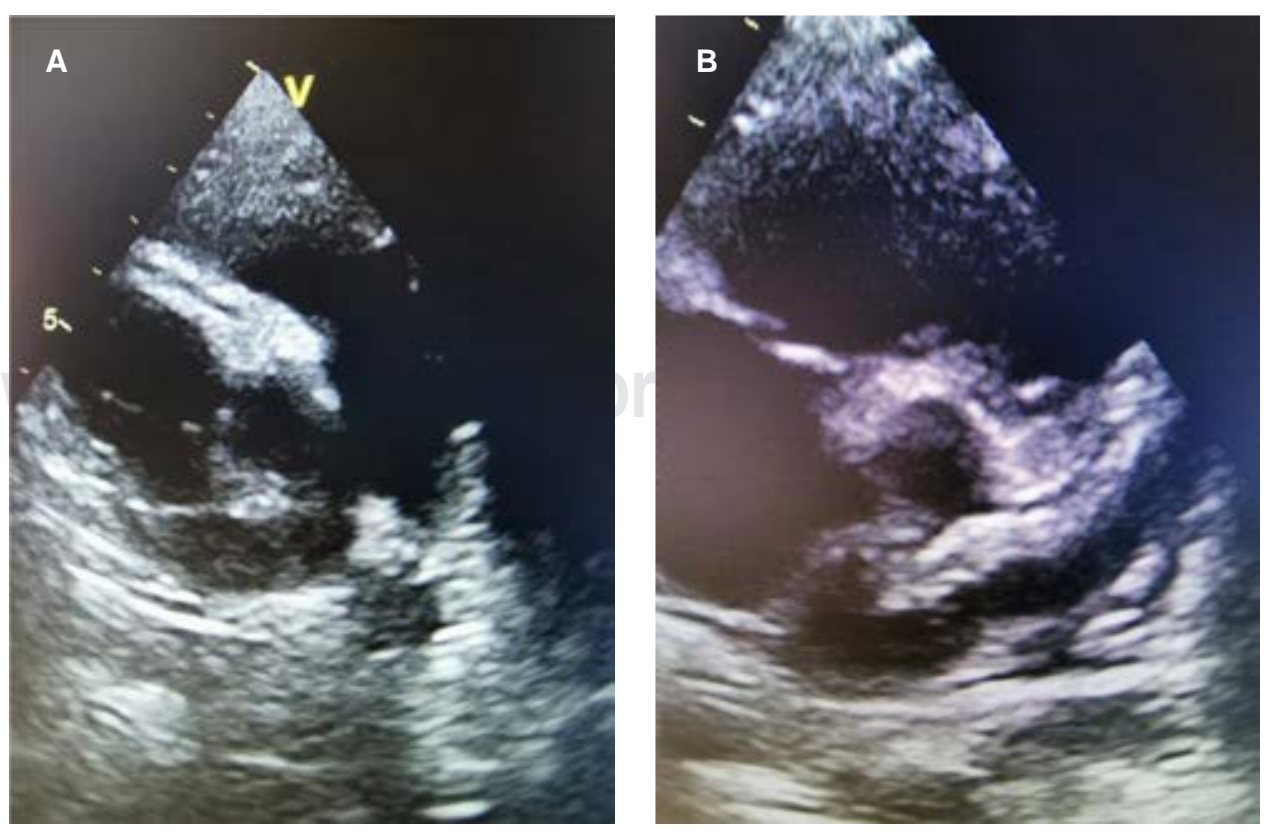
Vol. 29, Núm. 2・ Mayo-Agosto 2020

que comentamos, el paciente manifestó las características de enfermedad de Kawasaki clásico, el cual respondió de forma favorable a dosis única de inmunoglobulina humana con altas dosis de ácido acetilsalicílico, sin presentar lesión coronaria hasta el momento su último seguimiento en la tercera semana posterior a su alta.

\section{CONCLUSIÓN}

Los síntomas de COVID-19 son similares en niños y adultos. Hasta la fecha, la presentación pediátrica más común de COVID-19 es una serie de signos y síntomas que incluyen desde completamente asintomáticos a los síntomas de infección aguda del tracto respiratorio superior, como fiebre, fatiga, tos seca, odinofagia, rinorrea, congestión y dificultad para respirar. En casos más severos, los síntomas pueden incluir síntomas gastrointestinales y los pacientes pueden progresar a insuficiencia respiratoria, choque, alteraciones de la coagulación y falla renal. En comparación con los niños más pequeños, los adolescentes y los adultos tienen un mayor riesgo de morbilidad y mortalidad, con factores de riesgo particulares que incluyen afecciones preexistentes, especialmente diabetes, obesidad e hipertensión.

Han pasado más de 50 años desde que el Dr. Tomisaku Kawasaki reportó los primeros casos en Japón, de la enfermedad que desde entonces lleva su apellido. ${ }^{26}$ La causa de la EK sigue siendo desconocida. La hipótesis más aceptada es una respuesta aberrante del sistema inmune a uno o más patógenos no identificados en pacientes genéticamente predispuestos. ${ }^{27,28}$

Un estudio retrospectivo de dos años realizado en el noreste de Italia calculó una incidencia de 14.7 casos por cada 100,000 niños menores de cinco años. Se reportaron una gran cantidad de casos de enfermedades similares a Kawasaki en la provincia de Bérgamo luego de la epidemia de SARS-CoV-2, con una incidencia mensual que es al menos 30 veces mayor que la incidencia mensual de los cinco años anteriores, y tiene un comienzo claro después del primer caso de COVID-19 diagnosticado en esa región. El segundo grupo de pacientes, diagnosticado después de la aparición del SARS-CoV-2, mostró evidencia de seroconversión al virus SARS-CoV-2 en la mayoría de los pacientes. ${ }^{29}$ Esto sugiere que la familia del coronavirus podría representar uno de los desencadenantes de la enfermedad de Kawasaki, ya que el SARS-CoV-2 es una cepa particularmente virulenta capaz de provocar una respuesta inmune poderosa en el huésped.

El efecto proinflamatorio del SARS-CoV-2 se ha informado en adultos con las complicaciones respiratorias más graves de COVID-19. ${ }^{30}$

Sin embargo, la enfermedad similar a Kawasaki descrita en Bérgamo, Italia sigue siendo una condición rara, que probablemente no afecta a más de uno de cada
1,000 niños expuestos al SARS-CoV-2. Esta estimación se basa en los datos limitados de la serie de casos en esa región. ${ }^{29}$

En México, hasta el momento de la publicación de este artículo, no hay datos suficientes para conocer la incidencia de infección por SARS-CoV-2 y enfermedad de Kawasaki o enfermedades similares a Kawasaki. Es nuestro interés contribuir a la experiencia acumulada en nuestra área y aportar elementos de investigación para la comprensión de la multifacética expresión clínica que hasta el momento nos reta el SARS-CoV-2.

\section{BIBLIOGRAFÍA}

1. Se confirma en México caso importado de coronavirus COVID-19. Disponible en: https://www.gob.mx/salud/ prensa/077-se-confirma-en-mexico-caso-importado-decoronavirus-covid-19?idiom=es

2. Actualización epidemiológica. Nuevo coronavirus (COVID-19). 28 de febrero de 2020. Organización Panamericana de la Salud. Disponible en: https://www. paho.org/sites/default/files/2020-02/2020-feb-28-pheactualizacion-epi-covid19.pdf

3. Alocución de apertura del Director General de la OMS en la rueda de prensa sobre la COVID-19 celebrada el 11 de marzo de 2020. Disponible en: https://www.who.int/es/dg/ speeches/detail/who-director-general-s-opening-remarks-atthe-media-briefing-on-covid-19---11-march-2020

4. Secretaría de Salud. Proceso de prevención de infecciones para las personas con COVID-19 (enfermedad por SARSCoV-2) contactos y personal de salud. CDMX: s.n., 2020. Lineamientos.

5. The Novel Coronavirus Pneumonia Emergency Response Epidemiology Team. The epidemiological characteristics of an outbreak of 2019 novel coronavirus diseases (COVID-19)China, 2020. China CDC Weekly. 2020; 2 (8): 113-122.

6. Dirección General de Epidemiología. Datos Abiertos COVID-19 [base de datos al 29/04/2020]. Secretaría de Salud; 2020.

7. CDC COVID-19 Response Team. Coronavirus Disease 2019 in Children - United States, February 12-April 2, 2020. MMWR Morb Mortal Wkly Rep. 2020; 69 (14): 422-426. doi: 10.15585/mmwr.mm6914e4.

8. Lu X, Zhang L, Du H et al. SARS-CoV-2 infection in children. N Engl J Med. 2020; 382 (17): 1663-1665.

9. Colonna C, Monzani NA, Rocchi A, Gianotti R, Boggio F, Gelmetti C. Chilblain-like lesions in children following suspected COVID-19 infection. Pediatr Dermatol. 2020; 10.1111/pde.14210.

10. Rowley AH, Shulman ST. The epidemiology and pathogenesis of Kawasaki disease. Front Pediatr. 2018; 6: 374.

11. McCrindle BW, Rowley AH, Newburger JW et al. Diagnosis, treatment, and long-term management of kawasaki disease: a scientific statement for health professionals from the American Heart Association. Circulation. 2017; 135: e927-e999. doi: 10.1161/CIR.0000000000000484.

12. Barrios Tascón A, Centeno Malfaz F, Rojo Sombrero H, Fernández-Cooke E, Sánchez-Manubens J, Pérez-Lescure Picarzo $\mathrm{J}$ et al. Consenso nacional sobre el diagnóstico, tratamiento y seguimiento cardiológico de la enfermedad de Kawasaki. An Pediatr (Barc). 2018; 89: 188.e1-188.e22.

13. Pediatric Intensive Care Society. PICS Statement: Increased number of reported cases of novel presentation of multi- 
Vol. 29, Núm. 2 • Mayo-Agosto 2020

system inflammatory disease. [April 27, 2020] Available in: https://picsociety.uk/wpcontent/uploads/2020/04/PICSstatement-re-novel-KD-C19-presentation-v2-27042020.pdf

14. Shulman ST. Kawasaki disease. In: Feigin RD, Cherry JD, editors. Textbook of pediatrics infectious disease. 5th ed. Philadelphia: Saunders; 2004. pp. 1055-1074.

15. Kawasaki T. Acute febrile mucocutaneous syndrome with lymphoid involvement with specific desquamation of the fingers and toes in children. Arerugi. 1967; 16: 178-222.

16. Maconochie IK. Kawasaki disease. Archives of Disease in Childhood - Education and Practice Edition. 2004; 89: ep3-ep8.

17. Newburger JW, Takahashi M, Gerber MA et al. Diagnosis, treatment, and long-term management of Kawasaki disease: a statement for health professionals from the Committee on Rheumatic Fever, Endocarditis and Kawasaki Disease, Council on Cardiovascular Disease in the Young, American Heart Association. Circulation. 2004; 110: 2747-2771.

18. Son MBF, Newburger JW. Kawasaki disease. Pediatr Rev. 2018; 39 (2): 78-90. doi: 10.1542/pir.2016-0182.

19. Rowley AH, Baker SC, Shulman ST et al. Detection of antigen in bronchial epithelium and macrophages in acute Kawasaki disease by use of synthetic antibody. J Infect Dis. 2004; 190 : 856-865.

20. Rowley AH, Shulman ST, Mask CA et al. IgA plasma cell infiltration of proximal respiratory tract, pancreas, kidney, and coronary artery in acute Kawasaki disease. $J$ Infect Dis. 2000; 182: 1183-1191.

21. Esper F, Shapiro ED, Weibel C, Ferguson D, Landry ML, Kahn JS. Association between a novel human coronavirus and Kawasaki disease. J Infect Dis. 2005; 191: 499-502.

22. Mcintosh K. Coronaviruses in the limelight. J Infect Dis. 2005; 191: 489-491.

23. Shimizu Ch, Shike H, Baker SC, García F, van der Hoek L, Kuijpers TW et al. Human coronavirus NL63 is not detected in the respiratory tracts of children with acute Kawasaki disease. J Infect Dis. 2005; 192: 1767-1771.
24. The Royal College of Paediatrics and Child Health is a registered charity in England and Wales (1057733) and Scotland (SCO 38299), 1 de mayo de 2020.

25. World Health Organization. Multisystem inflammatory syndrome in children and adolescents temporally related to COVID-19, Scientific Brief. [15 May 2020] Available in: https://www.who. int/news-room/commentaries/detail/multisystem-inflammatorysyndrome-in-children-and-adolescents-with-covid-19

26. Kawasaki T, Kosaki F, Okawa S, Shigematsu I, Yanagawa $H$. A new infantile acute febrile mucocutaneous lymph node syndrome (MLNS) prevailing in Japan. Pediatrics. 1974; 54: 271-276.

27. Shulman ST, Rowley AH. Kawasaki disease: insights into pathogenesis and approaches to treatment. Nat Rev Rheumatol. 2015; 11: 475-482.

28. Nakamura $Y$, Yashiro M, Uehara $R$ et al. Epidemiologic features of Kawasaki disease in Japan: results of the 20092010 nationwide survey. J Epidemiol. 2012; 22: 216-221.

29. Marchesi A, Tarissi de Jacobis I, Rigante D et al. Kawasaki disease: guidelines of the Italian Society of Pediatrics, part I - definition, epidemiology, etiopathogenesis, clinical expression and management of the acute phase. Ital $J$ Pediatr. 2018; 44: 102.

30. McGonagle D, Sharif K, O'Regan A, Bridgewood C. The role of cytokines including interleukin-6 in COVID-19 induced pneumonia and macrophage activation syndrome-like disease. Autoimmun Rev. 2020; 19 (6): 102537.

\author{
Dirección para correspondencia: \\ Adoniram Carrasco Castillo \\ Calle Crespo Núm. 810, \\ Col. Centro, 68000, \\ Oaxaca, Oaxaca. \\ Teléfono: 951-198-4235 \\ E-mail: respirar@live.com.mx
}

